\title{
CONTRIBUIÇÕES DA DANÇA NA FORMAÇÃO INICIAL DE PROFESSORES DE EDUCAÇÃO FÍSICA DA UNIVERSIDADE FEDERAL DO PIAUI'
}

\author{
José Carlos dos Santos \\ Universidade Federal do Triângulo Mineiro Uberaba, Minas Gerais, Brasil \\ Janete de Páscoa Rodrigues \\ Universidade Federal do Piauí, Teresina, Piauí, Brasil \\ Simone Silva Santos Nery \\ Universidade Federal do Piauí, Teresina, Piauí, Brasil \\ Érika Priscila de Sousa Silva \\ Universidade Federal do Piauí, Teresina, Piauí, Brasil \\ Agda Pereira Nunes \\ Universidade Federal do Piauí, Teresina, Piauí, Brasil \\ Aline de Freitas Brito \\ Universidade Federal do Piauí, Teresina, Piauí, Brasil
}

\begin{abstract}
Resumo
O estudo conheceu e analisou as contribuições das atividades desenvolvidas por meio do projeto "Corpo de Dança da UFPI" na formação profissional dos acadêmicos do curso de Educação Física da Universidade Federal do Piauí. A pesquisa qualitativa usou o método analítico e descritivo e foi realizada por meio de um questionário aplicado a 14 acadêmicos. Os resultados mostraram que a maioria dos participantes atuava na área de dança, que as experiências adquiridas por meio do projeto são relevantes e contribuíram no desenvolvimento profissional em áreas que transcendem o campo de atuação em dança. Conclui-se que a participação dos acadêmicos no "Corpo de Dança da UFPI" proporcionou conhecimentos que ampliaram suas potencialidades e possibilidades de atuação no mercado.
\end{abstract}

Palavras-chave: Dança. Educação Física. Formação profissional.

\section{Introdução}

A dança, ao longo dos anos, tem se apresentado como uma grande manifestação cultural, social e artística na vida cotidiana do ser humano. Ela ocupa espaços também dentro das

\footnotetext{
${ }^{1} \mathrm{O}$ presente trabalho não contou com apoio financeiro de nenhuma natureza para a sua realização.
} 
produções sociais e científicas, revelando-se como um produto e fator da cultura. Assim, a dança está associada a uma cadeia de condições sociais de estruturas influentes (SANTOS et al., 2016; SANTOS et al., 2015).

No âmbito da educação, a dança tem assumido o papel de possibilitar a compreensão da capacidade de movimento. O que favorece sua realização com maior inteligência, autonomia, responsabilidade e sensibilidade (CORREAA; NASCIMENTO, 2013). Portanto, torna-se importante que o professor de Educação Física permaneça atento às diversas formas de manifestação das danças na contemporaneidade (GUZZO et al., 2015).

Entretanto, o processo de ensino-aprendizagem dentro dos cursos de formação inicial de professores de Educação Física ainda tem reproduzido a dança como um modelo de "repetição de movimento". E embora ela seja historicamente uma das mais antigas manifestações socioculturais da humanidade, sua participação tem se mostrado ainda de forma muito tímida nos cursos de licenciatura em Educação Física (SOUSA; HUNGER; CARAMASCHI, 2014).

Pereira (2007) ressalta que, apesar de a Educação Física buscar fortalecer o panorama da dança no contexto da formação inicial de seus professores, ainda são poucas as produções científicas que tratam dos subsídios da dança para a formação de novos profissionais no campo da educação.

Fosaluza (2012) e Ehrenberg (2003) acrescentam que, apesar da riqueza e do contexto histórico da presença da dança nas sociedades humanas, ainda há muitos problemas no trato com a dança na atuação do profissional de Educação Física, especialmente no contexto da licenciatura. Ugaya (2011) e Ehrenberg (2008; 2003) lembram que a dança presente nos cursos de formação de professores Educação Física não visa formar profissionais em dança, mas proporcionar conhecimentos, vivências e reflexões acerca do papel dessa atividade no desenvolvimento motor, social e afetivo dos seus praticantes. A dança, nessa perspectiva, precisa buscar desenvolver a autonomia, o senso estético e crítico nos alunos, de forma a torná-los cidadãos mais conscientes. No entanto, vê-se que os profissionais em Educação Física estão ingressando no mercado de trabalho totalmente inseguros e com receio de não conseguirem desenvolver um bom trabalho com dança (PEREIRA; HUNGER, 2009).

Por outro lado, os acadêmicos que vivenciam a dança de forma adequada durante a fase de formação profissional poderão tornar-se capazes de ensinar esse conteúdo com maior segurança e propriedade em suas aulas de Educação Física. Com isso, permitirão que seus alunos apreciem e construam novos significados e sentidos para essas danças a partir das realidades vivenciadas por eles (ALVES et al., 2015).

Sousa, Hunger e Caramaschi (2014) alertam que os profissionais em formação inicial não devem procurar priorizar, em suas práticas de dança, a execução de movimentos extremamente corretos e perfeitos. É necessário que busquem refletir sobre o ensino da dança, principalmente por esta fazer parte do processo de sua formação no ensino superior (UGAYA, 2011; EHRENBERG, 2008; 2003).

Diante disso, surgem indagações que norteiam o desenvolvimento desta investigação no contexto da dança como conteúdo da Educação Física, as quais são: que contribuições os projetos propostos pelas instituições brasileiras de ensino superior estão oferecendo no processo de formação de professores de Educação Física para o trato com a dança no mercado de trabalho? Além disso, como tais projetos atuam junto aos acadêmicos, de forma a prepará-los para a aplicação significativa desse conteúdo, contemplando as esferas do ensino, da pesquisa e da extensão?

Nessa perspectiva, foi criado no curso de Educação Física da Universidade Federal do Piauí (UFPI) o projeto "Corpo de Dança da UFPI", com o objetivo de estabelecer uma interrelação pragmática entre a dança e os demais conteúdos da Educação Física. Portanto, o projeto visou oferecer aos futuros profissionais da área experiências concretas de dança no cenário pedagógico da Educação Física. Nessa perspectiva, Godoy et al. (2012) ressaltam que é 
papel da universidade formar profissionais capazes de promover a produção e a reflexão de conhecimentos, nos aspectos educacionais, sociais e/ou culturais.

Já Betti (1992) defende que projetos dessa natureza são importantes na formação inicial dos professores de Educação Física por proporcionarem vivências extracurriculares por meio de atividades formais ou informais, além de estabelecer uma relação dialética entre teoria e prática. Além disso, esses projetos geralmente valorizam as experiências adquiridas pelos acadêmicos antes de ingressarem no curso superior.

Sendo assim, o projeto "Corpo de Dança da UFPI" apresenta sua relevância por contribuir no processo de formação inicial dos estudantes de Educação Física dessa universidade, possibilitando um melhor desempenho profissional desses alunos no ensino da dança, seja na Educação Física escolar, seja fora dela. Nesse propósito, o "Corpo de Dança da UFPI" buscou desenvolver atividades teóricas e práticas de maneira articulada num mesmo projeto, ao envolver simultaneamente ensino, pesquisa e extensão.

Dito isso, o objetivo deste estudo é conhecer e analisar as contribuições das atividades de dança desenvolvidas por meio do projeto "Corpo de Dança da UFPI" na formação profissional dos acadêmicos do curso de Licenciatura em Educação Física da Universidade Federal do Piauí.

\section{Percurso metodológico}

Esta pesquisa foi desenvolvida num viés qualitativo. Minayo (2004) afirma que um estudo qualitativo é aquele que se aplica à história das relações, das representações, das crenças, das percepções e das opiniões, produtos das interpretações que as pessoas fazem de como vivem, constroem os outros e a si mesmas.

Nessa vertente, empregaram-se os métodos analítico e descritivo. As pesquisas analíticas são descritas por Thomas, Nelson e Silverman (2012) como sendo aquelas que envolvem o estudo e a avaliação aprofundados de informações disponíveis, na tentativa de explicar as razões e o contexto de um fenômeno. Já Gerhadt e Silveira (2009) referem-se ao método descritivo como sendo aquele em que o investigador averigua uma série de informações sobre o que deseja pesquisar. Esse tipo de estudo busca descrever os fatos e os fenômenos de determinada realidade.

A amostra da pesquisa foi constituída por 14 estudantes do curso de Licenciatura em Educação Física da UFPI, integrantes do "Corpo de Dança da UFPI".

Após a aprovação pelo Comitê de Ética em Pesquisa Humana (CEP/UFPI), sob o parecer de número 50145115.0.0000.5214, atendendo aos requisitos da Resolução 466/12, do Conselho Nacional de Saúde do Brasil, os indivíduos selecionados foram informados dos objetivos e procedimentos da pesquisa. Concordando em participar, assinaram o Termo de Consentimento Livre e Esclarecido (TCLE).

Os critérios de inclusão dos participantes na investigação foram: ser estudante de Licenciatura em Educação Física da UFPI; ser integrante do "Corpo de Dança da UFPI" no mínimo há um ano; ter mais de 18 anos de idade, e ter assinado o TCLE. Já os critérios de exclusão foram: não ser estudante de Licenciatura em Educação Física da UFPI; não ser integrante do "Corpo de Dança da UFPI" no mínimo há um ano; ter menos de 18 anos de idade e não ter assinado o TCLE.

Na coleta de dados, foi utilizado um questionário adaptado de Fosaluza (2012), por meio do qual os alunos foram questionados sobre o tempo de participação no projeto; o campo de atuação profissional no momento da pesquisa; as experiências de atuação profissional na área de dança; as vivências com dança antes do ingresso na universidade; as contribuições do projeto na formação profissional dos participantes; os fatores motivadores para o ingresso no projeto, e as contribuições do projeto no futuro profissional dos acadêmicos. 
Para tanto, a pesquisa desenvolveu-se nas seguintes etapas:

1 - identificação e localização dos participantes da pesquisa: os acadêmicos foram localizados nos dias de realização das atividades do projeto, que aconteciam na sala de dança do Setor de Esportes da UFPI;

2 - agendamento e entrega do TCLE aos participantes: todos os TCLE foram entregues e assinados pelos acadêmicos na sala de dança;

3 - aplicação dos questionários: os acadêmicos levaram o questionário para suas casas e o devolverem devidamente respondidos uma semana após a sua entrega.

Cumpridas essas etapas, os resultados foram tratados por meio da técnica de análise de conteúdo. Segundo Bardin (2010), esta consiste em um conjunto de técnicas de análise das comunicações visando obter, por meio de procedimentos sistemáticos e objetivos de descrição do conteúdo das mensagens, indicadores (quantitativos ou não) que permitem a inferência de conhecimento relativo às condições de produção/recepção (variáveis inferidas) da mensagem. Em seguida, empreendeu-se o processo de análise das falas dos respondentes a partir das palavras e das frases constituintes de suas narrativas. Procurou-se identificar sentidos e intenções presentes no texto com o propósito de comparar, selecionar e avaliar as unidades de análise, buscando sempre reconhecer o que era essencial para o objetivo do estudo, conforme determina Bardin (2010) como procedimento na análise de conteúdo.

\section{Resultados e discussão}

No que diz respeito aos resultados desta investigação, verificou-se que a maioria dos acadêmicos pesquisados participou do projeto desde sua criação em 2014, até o período de realização da pesquisa, conforme ilustra o Quadro 1:

Quadro1- Tempo de participação dos alunos no "Corpo de Dança da UFPI"

\begin{tabular}{|cc|}
\hline Graduando & Período de participação \\
\hline EDF 1 & $2014-2016$ \\
EDF 2 & $2014-2016$ \\
EDF 3 & $2014-2016$ \\
\hline EDF 4 & $2014-2015$ \\
\hline EDF5 & $2014-2015$ \\
EDF 6 & $2014-2016$ \\
\hline EDF 7 & $2014-2016$ \\
EDF 8 & $2014-2015$ \\
EDF 9 & $2014-2015$ \\
\hline EDF 10 & $2014-2016$ \\
\hline EDF 11 & $2015-2016$ \\
EDF 12 & $2014-2016$ \\
\hline EDF 13 & $2014-2016$ \\
\hline EDF 14 & $2014-2016$ \\
\hline
\end{tabular}

Legenda: EDF corresponde aos participantes do "Corpo de Dança da UFPI"

Fonte:Elaborado pelos autores (2016)

\section{Áreas de atuação profissional dos participantes da pesquisa}

Na questão referente à atuação profissional dos 14 integrantes do "Corpo de Dança da UFPI" investigados, verificou-se que a área em que eles mais atuam é musculação (seis alunos); em seguida, foi citada a ginástica aeróbica (cinco deles); a função de bailarino/coreógrafo é desempenhada por dois participantes do estudo; dois acadêmicos apenas estudam. Já Educação Física escolar, por meio do Programa Institucional de Bolsa de Iniciação 
à Docência (PIBID), pole dance, treinamento funcional, natação, ator e atendente de telemarketing são funções desempenhadas por apenas um aluno em cada área dessas.

Quadro2 - Atuação profissional da amostra da pesquisa

\begin{tabular}{|cc|}
\hline Graduando & Áreas de atuação profissional \\
\hline EDF 1 & Coreógrafo e bailarino \\
EDF 2 & Musculação \\
EDF 3 & Musculação e ginástica aeróbica \\
EDF 4 & Musculação \\
EDF5 & Bolsista do PIBID - Educação Física escolar \\
EDF 6 & Ginástica aeróbica e musculação \\
EDF 7 & Musculação \\
EDF 8 & Apenas estuda \\
EDF 9 & Musculação, ginástica aeróbica e treinamento funcional \\
EDF 10 & Coreógrafo, bailarino e ator \\
EDF 11 & Ginástica aeróbica \\
EDF 12 & Apenas estuda \\
EDF 13 & Atendente de telemarketing \\
EDF 14 & Pole dance \\
\hline
\end{tabular}

Legenda: EDF, corresponde aos participantes do "Corpo de Dança da UFPI"

Fonte: Elaborado pelos autores (2016)

Esses resultados revelaram que as atividades rítmicas e expressivas servem de base para o desempenho profissional da metade dos acadêmicos estudados. Ginástica aeróbica, pole dance e funções de bailarino/coreógrafo são atividades profissionais desenvolvidas por 7 dos 14 estudantes de Educação Física participantes do "Corpo de Dança da UFPI".

Diante do exposto, pode-se observar que o mercado de trabalho requer profissionais com conhecimentos em dança. Contudo, o que se vê dentro dos cursos de graduação são alunos e professores com pouco interesse em atuar neste segmento, tanto como conteúdo educacional quanto como modalidade de exercício físico com foco na saúde. Nesse debate, Nanni (1995) expõe que a dança nos cursos de graduação deve estar relacionada aos outros campos de conhecimento, sendo tratada de forma a apontar seus diversos estilos, técnicas, escolas, características, importância sociocultural e reflexões acerca do processo de ensino nos diversos níveis escolares. Não obstante, Ugaya (2011) destaca que a dança muitas vezes é tratada em disciplinas denominadas atividades rítmicas e expressivas, ritmo e movimento, expressão corporal e, por isso, acaba não sendo trabalhada na Educação Física.

Importante destacar ainda, em face dos resultados, que grande parte dos participantes atua profissionalmente em esferas extraescolares (ginástica aeróbica, musculação, pole dance e outras). Nesse aspecto, é válido lembrar que se trata de estudantes de Licenciatura em Educação Física que estão desempenhando atividades profissionais em contextos fora das propostas curriculares de um curso de formação de professores para a educação básica, como é o caso do curso de Licenciatura em Educação Física da UFPI. Assim, corroborando essa ideia, Proscêncio (2008) constatou, em um estudo realizado com professores de Educação Física da rede pública da cidade de Londrina, que estes não aplicavam a dança na escola por se sentirem despreparados para isso.

Nessa mesma perspectiva, Rocha e Rodrigues (2007) verificaram em sua pesquisa que, embora os professores tenham revelado ter consciência acerca da importância do ensino da dança na educação básica, eles se mantêm presos às tradições, as normas e aos preconceitos que os impedem de trabalhar com a dança no contexto escolar. 
No que diz respeito aos acadêmicos estudados que não trabalham com dança (sete deles), eles justificaram esta situação pelo fato de não terem tido oportunidade para atuar na área.

Por enquanto, não estou atuando com a dança porque trabalho em uma academia de musculação e a parte de dança fica com outra pessoa (EDF2, 2016).

O meu desejo é trabalhar com a dança na academia, mas fui contratada como estagiária de musculação (EDF 7, 2016).

Diante das narrativas dos estudantes, fica evidente o desejo desses alunos de trabalhar na área de dança, embora se observe uma falta de oportunidades de atuação profissional vivenciada pelos alunos de Licenciatura em Educação Física da UFPI no ambiente escolar, não apenas no que se refere ao ensino do conteúdo dança, mas ao ensino dos demais componentes curriculares da Educação Física escolar.

\section{Experiências profissionais dos alunos na área específica de dança}

No que se refere àqueles estudantes que atuam profissionalmente com dança, averiguou-se que cinco deles têm experiência com balé clássico; três têm vivência profissionais com dança contemporânea, danças urbanas e danças populares; dois acadêmicos relataram experiências com jazz dance. Já dança afro e dança-teatro foram citadas como experiência profissional por um aluno para cada uma delas.

Esses resultados indicam que a participação dos alunos de Educação Física no projeto "Corpo de Dança da UFPI" apresentou-se como elemento facilitador na atuação desses profissionais na área da dança. $\mathrm{O}$ que revela o papel fundamental das atividades de extensão com propostas teórico-práticas na formação acadêmica dos graduandos, por promoverem, junto aos futuros professores, fazeres profissionais pautados numa multiplicidade de conteúdos, abandonando modelos de aulas formulados somente a partir de alguns esportes, situação muito comum no contexto da Educação Física escolar em todo o país.

De certo, muitos estudantes de Educação Física concluem seus cursos de graduação sem ter vivenciado qualquer atividade efetiva que envolva a dança como recurso de atuação no mercado de trabalho. Contudo, Nanni (2008) adverte que isso precisa ser revisto, uma vez que, nos dias de hoje, a dança não é privilégio de uma classe, mas uma forma de desenvolvimento e aprimoramento do ser humano, possibilitando enveredar para os caminhos da autorrealização do individuo. Neste sentido, Robatto (1994) lembra que a dança tem função de desenvolver nos indivíduos senso de coletividade, expressividade, ludicidade, espiritualidade, identificação cultural, ressignificação sociocultural, entre outros. 
Quadro3 - Atuação profissional dos estudantes em dança e em outras áreas

\begin{tabular}{|c|c|c|}
\hline Graduando & Atuação em dança & Atuação em outras áreas \\
\hline EDF 1 & $\begin{array}{c}\text { Dança contemporânea e dança } \\
\text { afro }\end{array}$ & - \\
\hline EDF 2 & Dança popular & Capoeira \\
\hline EDF 3 & Danças urbanas & Ginástica aeróbica \\
\hline EDF 4 & - & - \\
\hline EDF5 & - & - \\
\hline EDF 6 & $\begin{array}{l}\text { Balé clássico } \\
\text { Danças urbanas }\end{array}$ & Instrutor de musculação \\
\hline EDF 7 & Danças populares & Instrutor de musculação \\
\hline EDF 8 & Balé clássico & - \\
\hline $\begin{array}{l}\text { EDF } 9 \\
\text { EDF } 10\end{array}$ & $\begin{array}{c}- \\
\text { Dança contemporânea, jazz } \\
\text { dance, dança-teatro e danças } \\
\text { populares }\end{array}$ & $\begin{array}{l}\text { Ginástica aeróbica, treinamento funcional } \\
\text { Ginástica aeróbica }\end{array}$ \\
\hline EDF 11 & - & - \\
\hline EDF 12 & $\begin{array}{l}\text { Balé clássico } \\
\text { Danças urbanas }\end{array}$ & - \\
\hline EDF 13 & Balé clássico & Instrutor de pole dance \\
\hline EDF 14 & $\begin{array}{c}\text { Balé clássico } \\
\text { Dança contemporânea e jazz. }\end{array}$ & Instrutor de ginástica \\
\hline
\end{tabular}

Fonte: Elaborado pelos autores (2016)

Percebeu-se que grande parte dos acadêmicos apresentam vivências na área da dança. Porém, é necessário atentar para o fato de que, nesse processo de formação inicial, é fundamental o acadêmico compreender os sentidos e as razões do ensino da dança na esfera da educação básica. O futuro professor precisa assumir o compromisso ético e social de educar seus alunos por meio da diversidade de experiências em dança como ferramentas educativas, não se limitando a repetições mecanizadas de passos de dança que perpetuam concepções dicotômicas e cartesianas sobre o corpo e seus movimentos. Por isso, Ehrenberg (2008) defende que os futuros professores devem adotar a dança em suas ações pedagógicas com a finalidade de envolver os alunos nas perspectivas da cultura corporal de movimento.

Barreto (2005) lembra que as concepções da Educação Física escolar no entendimento da cultura corporal devem formar indivíduos plenos e capazes de exercer sua cidadania. $\mathrm{Ne}$ les, a dança está introduzida no bloco de atividades rítmicas e expressivas caracterizadas como forma de comunicação e expressão. Assim, uma das propostas metodológicas sugeridas por Nanni (1995), em relação ao ensino da dança/educação, é propiciar ao aluno seu fazer criativo, pois, através do processo de criação, ele se tornará independente e estimulado a interagir com seu grupo social.

\section{Vivências dos participantes da pesquisa com dança antes do ingresso na UFPI}

Em relação às experiências dos graduandos com dança antes de ingressarem na universidade, verificou-se que a maioria dos alunos, nove deles, já tinham vivências com dança a partir de estilos livres. Balé clássico e dança contemporânea foram vivenciados pela segunda maior parcela dos estudantes (sete deles). Já as danças urbanas e a dança afro foram experiências vividas pelo menor número de graduandos pesquisados, apenas um, conforme ilustra o Quadro 4. 
Quadro 4 - Experiências dos graduandos com dança antes do ingresso na UFPI

\begin{tabular}{|c|c|c|c|c|c|c|c|c|}
\hline Grad. & Balé & Jazz & Contemporânea & $\begin{array}{c}\text { Estilo } \\
\text { livre }\end{array}$ & $\begin{array}{c}\text { Dança } \\
\text { urbana }\end{array}$ & $\begin{array}{c}\text { Dança } \\
\text { popular }\end{array}$ & Capoeira & $\begin{array}{c}\text { Dança } \\
\text { afro }\end{array}$ \\
\hline EDF 1 & $\bar{X}$ & & $\bar{X}$ & $\bar{X}$ & & $X$ & & $\bar{X}$ \\
\hline EDF 2 & & & & X & & & $X$ & \\
\hline EDF 3 & & & & $X$ & & & & \\
\hline EDF 4 & & & & $\mathrm{X}$ & & & & \\
\hline EDF5 & & & & $\mathrm{X}$ & & & & \\
\hline EDF 6 & X & & X & & $X$ & & & \\
\hline EDF 7 & & & X & $X$ & & $\mathrm{X}$ & & \\
\hline EDF 8 & X & & & & & & & \\
\hline EDF 9 & & & & & & & & \\
\hline EDF 10 & X & X & X & $X$ & & X & X & \\
\hline EDF 11 & & & & & & & & \\
\hline EDF 12 & $X$ & $X$ & $X$ & X & & & & \\
\hline EDF 13 & $X$ & & $X$ & & & & & \\
\hline EDF 14 & $X$ & $X$ & $X$ & X & & & & \\
\hline
\end{tabular}

Fonte: Elaborado pelos autores (2016)

Embora a maioria dos acadêmicos investigados apresente algum tipo de experiência com dança, nenhum deles apresentou formação profissionalizante na área antes de ingressar na universidade. Brasileiro (2009) alerta que o mais importante nesse cenário seria compreender a forma com que os profissionais de Educação Física se aproximam do trato com o conhecimento de dança na escola, considerando a atual organização que ela apresenta e o tipo de formação que esses professores recebem, seja em uma formação na qual a dança é parte constitutiva, seja em uma formação em que ela é a centralidade.

Diante disso, acredita-se que as experiências adquiridas pelos acadêmicos por meio de suas participações no "Corpo de Dança da UFPI" tenham influenciado sobremaneira em suas escolhas e condições profissionais para atuar na área da dança.

\section{Contribuições do "Corpo de Dança da UFPI" na formação dos graduandos}

De acordo com a totalidade dos universitários pesquisados, a participação deles no "Corpo de Dança da UFPI" foi fundamental para a aquisição de conhecimentos acerca de dança, ao lhes oferecer a oportunidade de experimentar vivências com metodologias de ensino tanto de caráter teórico como prático. A dança como elemento central na proposta do "Corpo de Dança da UFPI" foi tratada com base em atividades de pesquisa, de extensão e em estratégias pedagógicas com foco na construção do senso crítico e reflexivo sobre o conteúdo dança, como ferramenta de educação. 
Quadro5 - Contribuições do "Corpo de Dança da UFPI" na formação profissional dos graduandos

\begin{tabular}{|ccccccc|}
\hline Graduando & Jazz & Contemporânea & Estilo livre & $\begin{array}{c}\text { Danças } \\
\text { urbanas }\end{array}$ & $\begin{array}{c}\text { Danças } \\
\text { populares }\end{array}$ & $\begin{array}{c}\text { Dança } \\
\text { afro }\end{array}$ \\
\hline EDF 1 & $\mathrm{X}$ & $\mathrm{X}$ & $\mathrm{X}$ & $\mathrm{X}$ & $\mathrm{X}$ & $\mathrm{X}$ \\
EDF 2 & $\mathrm{X}$ & $\mathrm{X}$ & $\mathrm{X}$ & $\mathrm{X}$ & $\mathrm{X}$ & $\mathrm{X}$ \\
EDF 3 & $\mathrm{X}$ & $\mathrm{X}$ & $\mathrm{X}$ & $\mathrm{X}$ & $\mathrm{X}$ & $\mathrm{X}$ \\
EDF 4 & $\mathrm{X}$ & $\mathrm{X}$ & $\mathrm{X}$ & $\mathrm{X}$ & $\mathrm{X}$ & $\mathrm{X}$ \\
EDF5 & $\mathrm{X}$ & $\mathrm{X}$ & $\mathrm{X}$ & $\mathrm{X}$ & $\mathrm{X}$ & $\mathrm{X}$ \\
EDF 6 & $\mathrm{X}$ & $\mathrm{X}$ & $\mathrm{X}$ & $\mathrm{X}$ & $\mathrm{X}$ & $\mathrm{X}$ \\
EDF 7 & $\mathrm{X}$ & $\mathrm{X}$ & $\mathrm{X}$ & $\mathrm{X}$ & $\mathrm{X}$ & $\mathrm{X}$ \\
EDF 8 & $\mathrm{X}$ & $\mathrm{X}$ & $\mathrm{X}$ & $\mathrm{X}$ & $\mathrm{X}$ & $\mathrm{X}$ \\
EDF 9 & $\mathrm{X}$ & $\mathrm{X}$ & $\mathrm{X}$ & $\mathrm{X}$ & $\mathrm{X}$ & $\mathrm{X}$ \\
EDF 10 & $\mathrm{X}$ & $\mathrm{X}$ & $\mathrm{X}$ & $\mathrm{X}$ & $\mathrm{X}$ & $\mathrm{X}$ \\
EDF 11 & $\mathrm{X}$ & $\mathrm{X}$ & $\mathrm{X}$ & $\mathrm{X}$ & $\mathrm{X}$ & $\mathrm{X}$ \\
EDF 12 & $\mathrm{X}$ & $\mathrm{X}$ & $\mathrm{X}$ & $\mathrm{X}$ & $\mathrm{X}$ & $\mathrm{X}$ \\
EDF 13 & $\mathrm{X}$ & $\mathrm{X}$ & $\mathrm{X}$ & $\mathrm{X}$ & $\mathrm{X}$ & $\mathrm{X}$ \\
EDF 14 & $\mathrm{X}$ & $\mathrm{X}$ & $\mathrm{X}$ & $\mathrm{X}$ & $\mathrm{X}$ & $\mathrm{X}$ \\
\hline
\end{tabular}

Fonte: Elaborado pelos autores (2016)

Segundo Ugaya (2011), para romper com os preconceitos que a dança sofre no contexto do ensino da Educação Física, e promover uma formação de qualidade no âmbito dos profissionais iniciantes na área, é necessário que os professores universitários partam do pressuposto de que os acadêmicos já trazem uma herança cultural que foi construída ao longo das suas experiências de vida. Com isso, as ações pedagógicas dos professores formadores devem ofertar voz e direito aos acadêmicos para mostrarem que podem ser ouvidos por todos.

\section{Motivos para os estudantes ingressarem no "Corpo de Dança da UFPI"}

Os acadêmicos elencaram diversos motivos para o ingresso no "Corpo de Dança da UFPI". Dentre os mais representativos, estão argumentos como "aumentar as experiências em dança", "realizar pesquisas sobre a dança", "mostrar que a dança está presente no curso de Educação Física", entre outros. Segundo Sant'ana e Aroeira (2010), quando os professores de Educação Física se interessam pelo conteúdo dança, eles demonstram que não pretendem agir como um mero reprodutor de conhecimentos, mas como um educador sujeito de sua ação pedagógica, capaz de transformar, de pensar, de construir e de desenvolver conhecimentos em seu fazer educacional. 
Quadro 6 - Fatores motivadores para os graduandos ingressarem no "Corpo de Dança da UFPI"

\begin{tabular}{|cl|}
\hline Graduando & \multicolumn{1}{c|}{ Fator motivador } \\
\hline EDF 1 & $\begin{array}{l}\text { Expectativas em pesquisar a dança como área de conhecimento dentro do curso de Educação } \\
\text { Física, além de desenvolver ações artísticas e corporais dentro do espaço acadêmico. }\end{array}$ \\
EDF 2 & $\begin{array}{l}\text { O desejo de aprender danças diversas, melhorar a aprendizagem motora, com o intuito de ser } \\
\text { um profissional mais qualificado na área da dança e fazer novas amizades. }\end{array}$ \\
EDF 3 & $\begin{array}{l}\text { O forte desejo de adquirir experiência com a dança, além de alimentar uma paixão que sem- } \\
\text { pre tive na infância, mas que não havia tido oportunidade. }\end{array}$ \\
EDF 4 & $\begin{array}{l}\text { A principal razão foi por ter uma grande admiração pela dança, e por ter a oportunidade de } \\
\text { vivenciá-la com um caráter mais profissionalizante dentro do curso. }\end{array}$ \\
EDF5 & $\begin{array}{l}\text { Sempre tive muita afinidade com a dança, e meu sonho sempre foi poder trabalhar com esta } \\
\text { modalidade. }\end{array}$ \\
EDF 6 & $\begin{array}{l}\text { Foi pela questão de trabalhar o corpo como um todo, trabalhando também o psicológico e } \\
\text { proporcionando momentos de prazer e descontração. } \\
\text { Ter mais experiências sobre diversos estilos de dança e me manter realizando atividades com } \\
\text { o corpo, promovendo a melhora da minha saúde. }\end{array}$ \\
EDF 8 & $\begin{array}{l}\text { Interesse em aprofundar os conhecimentos sobre dança e por gostar de dançar. } \\
\text { Para adquirir experiência com a dança, pois nunca tive oportunidade na infância e na adoles- } \\
\text { cência, e percebi que na universidade eu poderia vivenciar isso. }\end{array}$ \\
EDF 10 & $\begin{array}{l}\text { A maior razão entre todas foi o imenso desejo de mostrar que a dança está muito mais presen- } \\
\text { te na Educação Física do que as pessoas possam imaginar. E por poder compartilhar meu } \\
\text { conhecimento como artista da dança. }\end{array}$ \\
EDu entrei para aprender a dançar. \\
EDF 11 13
\end{tabular}

Fonte: Elaborado pelos autores (2016)

\section{Contribuições do "Corpo de Dança da UFPI" na formação dos graduandos}

Todos os acadêmicos participantes do estudo disseram que o projeto contribuiu na carreira profissional deles, por ter possibilitado experiências diversas que transcendem o campo de atuação profissional apenas em dança.

A minha participação no projeto de Extensão Corpo de Dança da UFPI foi bastante significativa, pois me possibilitou entrar em contato com as pesquisas científicas, me oportunizou participar de organizações de eventos regionais e de poder publicar meus relatos de experiências dentro de eventos científicos (EDF 10, 2016).

Diante do exposto, esses futuros professores de Educação Física poderão aplicar as experiências adquiridas por meio das atividades de ensino, de pesquisa e de extensão, propostas no "Corpo de Dança da UFPI", na aplicação dos demais conteúdos da Educação Física. Dessa forma, a dança apresenta-se como dispositivo eficaz na formação acadêmica desses profissionais, contribuindo também para a otimização do processo de ensino aprendizagem dos esportes, das lutas, dos jogos e da própria dança, tratados como componentes igualmente importantes na cultura corporal do movimento.

Segundo Pereira e Hunger (2009), a justificativa dada por alguns professores de Educação Física pelo não uso da dança na disciplina é a formação ineficiente que a graduação oferece para a atuação nessa área. Contudo, Nanni (1998) defende que compete ao profissional o aprofundamento de seus conhecimentos e habilidades técnico-científicos, culturais e artísticos em dança, aprimorando cada vez mais seus atributos e valores como educador. A autora acrescenta que o ato de ingressar no ramo da dança exige que o professor, para obter 
resultados satisfatórios e positivos, permaneça pesquisando e investigando os preceitos da disciplina que envolve o corpo e buscando as particularidades da dança, seus parâmetros, componentes, metodologia e procedimentos de ensino.

Quadro7 - Contribuições do "Corpo de Dança da UFPI” na formação dos graduandos

\begin{tabular}{|c|c|}
\hline Graduando & Contribuições \\
\hline EDF 1 & $\begin{array}{l}\text { A vivência com os integrantes e suas diferenças foi a contribuição mais forte com a minha } \\
\text { formação. Tive a oportunidade de planejar e experimentar atividades e de montar traba- } \\
\text { lhos artísticos, e isso contribuiu para a formação de todos do grupo. }\end{array}$ \\
\hline EDF 2 & $\begin{array}{l}\text { Ele contribuiu para uma melhor formação profissional em Educação Física, e nas relações } \\
\text { artísticas e críticas como profissional da área de Educação Física. }\end{array}$ \\
\hline EDF 3 & $\begin{array}{l}\text { Contribuiu na bagagem de conhecimento sobre a dança, desde o motor (puramente mecâ- } \\
\text { nico) até o humano. Aprendi a ter disciplina, perseverança e me deu a oportunidade de } \\
\text { ministrar aulas de dança através das experiências com o pessoal do projeto. }\end{array}$ \\
\hline EDF 4 & $\begin{array}{l}\text { O corpo de dança me fez expressar meus sentimentos através da dança e até consegui } \\
\text { deixar de lado a timidez. }\end{array}$ \\
\hline EDF5 & $\begin{array}{l}\text { A minha participação foi muito importante, tanto pelo lado pessoal quanto profissional. } \\
\text { Pelo pessoal foi porque me senti liberta e com bastante prazer, onde pude colocar tudo } \\
\text { que me afligia. Já pelo lado profissional foi ainda mais importante, pois eu não tinha tanta } \\
\text { experiência com a dança, nem com estudos teóricos e estudos de técnicas de dança. Então } \\
\text { pude aprender e desenvolver meu potencial no grupo. }\end{array}$ \\
\hline EDF 6 & $\begin{array}{l}\text { Contribuiu de forma significativa, levando a um grande crescimento pessoal e profissio- } \\
\text { nal, fazendo com que houvesse maiores atuações na área da dança e diferentes estudos } \\
\text { relacionados à mesma. }\end{array}$ \\
\hline EDF 7 & $\begin{array}{l}\text { O projeto de extensão em dança, além de promover meu bem-estar físico, mental e social, } \\
\text { me trouxe experiências em diversos estilos de dança. }\end{array}$ \\
\hline EDF 8 & $\begin{array}{l}\text { Saber expressar em qualquer ambiente minhas opiniões, meus conceitos, independente se } \\
\text { for um diálogo ou dança, aprender a improvisar, a ter segurança de muitas pessoas, enfim, } \\
\text { aprendi a ser "sem vergonha". }\end{array}$ \\
\hline EDF 9 & $\begin{array}{l}\text { O corpo de dança me fez perceber que meu corpo é criativo, que eu posso fazer dança } \\
\text { apesar das limitações físicas. }\end{array}$ \\
\hline EDF 10 & $\begin{array}{l}\text { A minha participação no projeto de Extensão Corpo de Dança da UFPI foi bastante signi- } \\
\text { ficativa, pois me possibilitou entrar em contato com as pesquisas científicas, me oportuni- } \\
\text { zou participar de organizações de eventos regionais e de poder publicar meus relatos de } \\
\text { experiências dentro de eventos científicos. }\end{array}$ \\
\hline EDF 11 & $\begin{array}{l}\text { Serviu para me conhecer melhor, e para mostrar que a dança é muito mais que se movi- } \\
\text { mentar apenas, ela também é estudo e sacrifício. }\end{array}$ \\
\hline EDF 12 & $\begin{array}{l}\text { A minha participação no corpo de Dança da UFPI me fez acreditar que posso aliar o co- } \\
\text { nhecimento da dança junto com os conhecimentos da Educação Física e realizar um traba- } \\
\text { lho maior sobre o corpo dos alunos. }\end{array}$ \\
\hline EDF 13 & Contribuiu para dinamizar meu potencial criativo. \\
\hline EDF 14 & $\begin{array}{l}\text { A participação no projeto de extensão corpo de dança me possibilitou construir meu TCC } \\
\text { envolvendo a temática dança e sua relação com o stress. }\end{array}$ \\
\hline
\end{tabular}

Fonte: Elaborado pelos autores (2016)

\section{Considerações finais}

Constatou-se nesta pesquisa que a maioria dos estudantes de Licenciatura em Educação Física da UFPI, componentes do "Corpo de Dança da UFPI", atuavam profissionalmente na área de dança e tinham alguma experiência com dança antes de ingressarem no curso de graduação. Além disso, todos os graduandos confirmam que a participação no projeto lhes proporcionou experiências tanto teóricas como práticas para atuar no mercado de trabalho com a dança de maneira crítica, reflexiva e criativa. Isso possibilitou aos estudantes construírem uma ação docente pautada em metodologias de ensino num viés humanista, levando em 
consideração os saberes preexistentes dos sujeitos sociais envolvidos no processo de ensino e aprendizagem da dança.

A maioria dos acadêmicos atuava com atividades de musculação, ginástica aeróbica, balé clássico e outras. O que demonstra que, embora a metade deles estivesse trabalhando com atividades rítmicas e expressivas, esses profissionais de Educação Física estavam afastados dos espaços da educação básica, proposta central de formação profissional do Projeto Pedagógico do Curso de Licenciatura em Educação Física da UFPI.

Conclui-se, portanto, que a realização de projetos de extensão na área de dança, no âmbito dos cursos graduação em Educação Física, é de grande importância no processo de formação desses futuros professores por proporcionar conhecimentos a serem aplicados em contextos pragmáticos da educação.

\title{
THE CONTRIBUTIONS OF DANCE TO PHYSICAL EDUCATION TEACH- ERS' INITIAL FORMATION FROM "UNIVERSIDADE FEDERAL DO PIAUÍ"
}

\begin{abstract}
The study analyzed the contributions of the activities developed by the project "Corpo de Dança da UFPI". The qualitative research used the analytical and descriptive method and it was made through a questionnaire applied to 14 university students. The results showed that most of the participants worked in the dance area, as well as the acquired experiences through the project were relevant and contributed to the professional development in areas that transcend the dance field of work. To conclude, the students' participation in the "Corpo de Dança da UFPI" provided knowledge that improved their potentialities and also possibilities of performing in the working market.
\end{abstract}

Keywords: Dance. Physical Education. Professional formation.

\section{LOS APORTES DE LA DANZA EN LA FORMACIÓN INCIAL DE PROFESORES DE EDUCACIÓN FÍSICA DE LA UNIVERSIDAD FEDERAL PIAUÍ}

\section{Resumen}

El estudio conoció y analizó los aportes de las actividades desarrolladas a través del proyecto "Corpo de Dança da UFPI" en la formación profesional de los estudiantes del curso de Educación Física de la Universidad Federal de Piauí). La investigación cualitativa utilizó los métodos analítico y descriptivo y fue desarrollada a través de un cuestionario aplicado a14 estudiantes. Los resultados mostraron que la mayoría de los participantes actuaba en el área de danza, que las experiencias adquiridas a través del proyecto son importantes y contribuyeron para el desarrollo profesional en áreas que sobrepasan el campo de actuación de la danza. Concluimos que la participación de los estudiantes en el "Corpo de Dança da UFPI" proporcionó conocimientos que ampliaron potenciales y posibilidades de actuación en el mercado laboral.

Palabras clave: Danza. Educación Física. Formación profesional. 


\section{Referências}

ALVES, M. S.; FALCÃO, A. P. S. T.; BRASILEIRO, L. T.; MELO, M. S. T.; MEDEIROS, F. R. C. Ensino da dança no ensino fundamental II e ensino médio da rede estadual de RecifePE. Pensar a Prática, Goiânia, v. 18, n. 2, abr./jun. 2015.

BARDIN, L. Análise de conteúdo. Lisboa: Edições 70, LDA, 2010.

BARRETO, D. Dança...: ensino, sentidos e possibilidades na escola. 2. ed. Campinas, SP: Autores Associados, 2005.

BETTI, M. Perspectivas na formação profissional. In: MOREIRA, W. W. (Org.). Educação física \& esportes - perspectivas para o século XXI. Campinas: Papirus, 1992.

BRASILEIRO, L.T. Dança - educação física: (in) tensas relações. 2009. Tese (Doutorado em Educação) - Faculdade de Educação, Universidade Estadual de Campinas, Campinas, 2009.

CORREAA, J. F; NASCIMENTO, F. M. Ensino de dança no Rio Grande do Sul: um breve panorama. Conceição Conception, v. 1, n. 3, dez. 2013

EHRENBERG, M. C. A dança como conhecimento a ser tratado pela Educação Física escolar: aproximações entre formação e atuação profissional. 2003. 130f.

Dissertação (Mestrado) - Faculdade de Educação Física, Universidade Estadual de Campinas, Campinas-SP, 2003.

Os currículos de licenciatura em Educação Física: a dança em questão. 2008. Tese (Doutorado) - Faculdade de Educação Física, Universidade Estadual de Campinas, Campinas-SP, 2008

FOSAlUZA, N. C. Projetos de extensão em Dança UNESP/Rio Claro: contribuições à formação profissional dos estudantes de Educação Física. 2012. Trabalho de conclusão de curso (Bacharelado em Educação Física) - Instituto de Biociências, Universidade Estadual Paulista, Rio Claro, 2012.

GERHARDT, T. E; SILVEIRA, D. T. Métodos de pesquisa - Universidade Aberta do Brasil - UAB/UFRGS e pelo Curso de Graduação Tecnológica - planejamento e gestão para o desenvolvimento rural da SEAD/UFRGS. Porto Alegre: Editora da UFRGS, 2009.

GODOY, K. M. A.; ANDRADE, C. R.; SGARBI, F.; ALMEIDA, F. S.; ALVES, F. T.; MELLO JÚNIOR, R.; PIMENTA, R. A.. Multiplicando olhares sobre a dança na escola: construção de saberes e experiências em um curso de formação continuada para professores. IN: CONGRESSO NACIONAL DE PESQUISADORES EM DANÇA, 2. Anais.... São Paulo, 2012 .

GUZZO, M. S. L.; FEDERICI, C. A. G.; ROBLE, O. J.; TERRA, V. D. S.. Dança é política para a cultura corporal. Pensar a Prática, Goiânia, v. 18, n. 1, jan./mar. 2015.

NANNI, D. Dança educação - princípios, métodos e técnicas. Rio de Janeiro. Editora Sprint, 1995. 
. Dança educação - pré-escola à universidade. 2. ed. Rio de Janeiro: Sprint, 1998.

Dança educação - pré-escola à universidade. 5. ed. Rio de Janeiro: Sprint, 2008.

MARQUES, Isabel A. Dançando na escola. 6. ed. São Paulo: Cortez Editora, 2012.

MINAYO, M. C. S. Pesquisa social: teoria, método e criatividade. 23. ed. Petrópolis, RJ: Vozes, 2004.

PEREIRA, M. L.; HUNGER, C. F. Limites do ensino da dança na formação do professor de Educação Física. Revista Motriz, Rio Claro, v. 15, n. 4, p. 768-780, out./dez. 2009. Disponível em: <http://www.periodicos.rc.biblioteca.unesp.br/index.php/motriz/article/viewFile/2926/25>. Acesso em: 12 abr. 2016.

PEREIRA, M. L. A formação acadêmica do professor de Educação Física: em questão o conteúdo da dança. 2007. 187f. Dissertação (Mestrado em Ciências da Motricidade) - Instituto de Biociências, Universidade Estadual Paulista, Rio Claro, 2007.

PROSCÊNCIO, P.; SOUZA, A. Dança na educação infantil: um convite ao educador. In: SEMANA DA EDUCAÇÃO DA UNIVERSIDADE ESTADUAL DE LONDRINA, 10. Anais.... Londrina (PR), 2008.

ROBATTO, L. Dança em processo: a linguagem do indizível. Salvador: UFBA, 1994.

ROCHA, D.; RODRIGUES, G. M. A dança na escola. Revista Mackenzie de Educação Física e Esporte, v. 6, n. 3, p. 15-21, 2007.

SANTOS, J, C et al., Experiências e saberes da dança na formação inicial de professores de Educação Física. ACTAS, 2016.

SANTOS, R. F.; FERRAZ, S. C.; ALMEIDA, M. A. G. L.; GUTIERREZ, G. L. A dança como prática de lazer: algumas reflexões sobre homens, gênero e o balé clássico. Pensar a Prática, Goiânia, v. 18, n. 2, abr./jun. 2015.

SANT'ANA, S. A; AROEIRA, K. P. Profissional, professores de educação física e a dança: alguns apontamentos. Fiep Bulletin, v. 80, Special Edition, article I, 2010 .

SOUSA, N. C. P. de; HUNGER, D. A. C. F. CARAMASCHI, S. O ensino da dança na escola na ótica dos professores de Educação Física e de Arte. Revista Brasileira de Educação Física e Esporte, São Paulo, 2014.

THOMAS, J.R.; NELSON, J.K.; SILVERMAN, S.J. Métodos de pesquisa em atividade física. 6. ed. Porto Alegre: Artmed, 2012.

UGAYA. A. S. A dança na formação docente em educação física. 2011. Tese (Doutorado) - Faculdade de Educação Física, Universidade Estadual de Campinas, Campinas, 2011. 
Recebido em: 30/10/2016

Revisado em: 17/04/2017

Aprovado em: 30/08/2017

Endereço para correspondência:

alineebritoo@gmail.com

Aline Brito

Universidade Federal do Piauí,

Campus Universitário Ministro Petrônio Portella

Bairro Ininga

Coordenadoria de Comunicação Social,

64049-550-- Teresina - PI 